\title{
UM CISNE, DUAS FORÇAS: SOBRE APOLÍNEO E DIONISÍACO NA ÉTICA DO CONSUMO
}

\author{
ONE SWAN, TWO FORCES: ON APOLLONIAN AND \\ DIONYSIAN IN THE ETHIC OF CONSUMPTION \\ UN CISNE, DOS FUERZAS: POR APOLINNEO Y \\ DIONISÍACO EN LA ÉTICA DEL CONSUMO
}

Daniel B. Portugal*
Julia Salgado**
Marcos Beccari***

\section{Resumo}

Neste artigo, procuramos analisar uma possível cisão na ética contemporânea servindo-nos do modelo das forças conflituosas do apolíneo e do dionisíaco conforme propostas por Nietzsche. Analisamos e destacamos as orientaçôes éticas relacionadas ao consumo e aos conflitos subjetivos a elas relacionados. Para realizar tal estudo, usamos como ponto de partida uma análise do filme Cisne Negro (2010), de Darren Aronofsky, que traz à tona questóes centrais para a análise que nos propomos realizar, complementando-o, ainda, com outras referências literárias e publicitárias.

Palavras-chave: apolíneo; dionisíaco; ética; consumo.

\section{Abstract}

In this article we analyzed a possible division in contemporary ethic using the model of the conflicting forces of apollonian and Dionysian, as proposed by Nietzsche. We analyze and emphasize the ethical guidelines related to consumption and the subjective conflicts related to them. To develop this study our starting point was an analysis of the movie Black Swan (2010), by Darren Arono-

\footnotetext{
* Universidade Federal do Rio de Janeiro, Rio de Janeiro, RJ, Brasil.

** Universidade Federal do Rio de Janeiro, Rio de Janeiro, RJ, Brasil.

*** Universidade de Sáo Paulo, São Paulo, SP, Brasil.
} 
fsky, which brings up central questions to the analysis that we propose to accomplish. To complement our analysis we also use other references from literature and advertising.

Keywords: apollonian; Dionysian; ethic; consumption.

\section{RESUMEN}

En este artículo se analiza una posible división en la ética contemporánea utilizando el modelo de las fuerzas contradictorias de apolíneo y dionisíaco, según lo propuesto por Nietzsche. Analizamos las directrices éticas relacionadas con el consumo y los conflictos subjetivos relacionados con las mismas. Para desarrollar este estudio nuestro punto de partida fue un análisis de la película Cisne Negro (2010), de Darren Aronofsky, que nos lleva a cuestiones centrales para el análisis. Para complementar nuestro análisis también utilizamos otras referencias de la literatura y la publicidad.

Palabras clave: apolíneo; dionisíaco; ética; consumo.

Ao tentar analisar teoricamente os meandros subjetivos que permeiam a forma atual de nossa sociedade de consumo, Lipovetsky (2007) observa diversos paradoxos que lhe são característicos. Um desses paradoxos nos leva às pulsôes estéticas $^{1}$ delineadas por Nietzsche em $O$ nascimento da tragédia $(1872 / 2007)$ quais sejam, a apolínea e a dionisíaca. Neste artigo, propomos uma reflexão sobre a forma contemporânea de tal dualismo tomando como ponto de partida para tal reflexão o filme Cisne Negro (2010), de Darren Aronofsky.

Notadamente representativo do embate entre as pulsóes apolínea e dionisíaca nas subjetividades contemporâneas, Cisne Negro será o pano de fundo sobre o qual procuramos costurar a releitura de teorias à análise de outros produtos midiáticos - como filmes e peças publicitárias. A seleção do corpus justifica-se pela contribuição de seus conteúdos à reflexão sobre a atual ética que embasa o consumo como atividade central na busca de ideais. Atuamos, tal como propóe Mitchell (Portugal \& Rocha, 2009), como caçadores de textos e imagens - rastreamos atentamente aqueles que revelam de forma mais clara os valores que fundamentam seus discursos sobre o que seria uma vida boa, prazerosa, adequada ou feliz.

Em nossa análise de Cisne Negro, destacaremos as formas com que o apolíneo e o dionisíaco perpassam o conflito da protagonista. Começaremos com um breve resumo do filme, embora seja importante ressaltar que se trata de uma obra especialmente resistente à transcrição, uma vez que faz uso extenso da linguagem cinematográfica para tratar de questóes subjetivas. 
A protagonista de Cisne Negro é Nina: uma jovem bailarina integrante de uma companhia de balé nova-iorquina, reconhecida por seu diretor artístico (Leroy) e sua bailarina principal (Beth). Nina mora com a mãe, uma ex-bailarina que teve a carreira interrompida pela gravidez imprevista e que acaba transferindo para a filha expectativas frustradas de sucesso artístico. O filme começa mostrando a obsessão de Nina por seus treinos e sua performance: ela ensaia exaustivamente cada passo e cada movimento, ao limite de seus pés sangrarem.

A trama se inicia quando Leroy deve decidir a programação e o elenco de sua companhia de balé para o novo ano. O diretor julga que Beth, a primeira bailarina, está velha demais para ser a grande estrela e resolve substituí-la por uma bailarina mais jovem - o que, antes de qualquer coisa, espelha uma contemporânea tendência social: o "valor juventude" superando o "valor talento". A dançarina escolhida começará protagonizando uma nova versão de $O$ Lago dos Cisnes, idealizada por Leroy, na qual a mesma bailarina interpreta os papéis dos cisnes branco e negro.

O Lago dos Cisnes, como se sabe, conta a história da princesa Odette, que é enfeitiçada pelo mago Rothbart e transformada em um cisne branco, podendo ser libertada do feitiço somente por um homem que ame apenas a ela. Intimado por sua mãe a escolher uma esposa, o príncipe Siegfried é atraído pelo cisne e apaixona-se por Odette, fazendo-lhe juras de amor. Mas disposto a manter sua maldição intacta, Rothbart envia uma feiticeira também na forma de cisne - o cisne negro - para seduzir o príncipe Siegfried, impedindo-o de quebrar o feitiço de Odette, que, desesperada, suicida-se.

No balé idealizado por Leroy, o cisne branco se caracteriza por sua elegância e rigor formal na dança. Seus movimentos são contidos, minuciosos, precisos. O cisne negro, por sua vez, caracteriza-se por sua sensualidade e "naturalidade" no bailado. Seus movimentos são incontidos, impensados, como se o corpo da bailarina fosse tomado pela música e pela potência erótica. Cada um deles liga-se, portanto, a um dos impulsos estéticos descritos por Nietzsche $(1872 / 2007, \$ 1)$ :

Para nos aproximarmos mais desses dois impulsos, pensemo-los primeiro como os universos artísticos, separados entre si, do sonho e da embriaguez, entre cujas manifestaçôes fisiológicas cabe observar uma contraposição correspondente à que se apresenta entre o apolíneo e o dionisíaco.

O apolíneo aproxima-se do universo onírico porque leva à figuraçáo, à delimitação formal, à ordem, à separação do caótico "todo" que seria o mundo 
em sua essência. Revelando-se mais intensamente nas formas mais belas, mais delineadas, o apolíneo nos leva a deter-nos na representação².

O dionisíaco, por outro lado, aproxima-se da embriaguez porque transborda os limites da representação, misturando e arrastando tudo para o caos essencial. Se, ao terror da dissolução do mundo da aparência, do mundo em que vivemos "conscientemente" - "se a esse terror acrescentarmos o delicioso êxtase que, à ruptura do principium individuationis ${ }^{3}$, ascende do fundo mais íntimo do homem, sim, da natureza, ser-nos-á dado lançar um olhar à essência do dionisíaco [...]" (Nietzsche, 1872/2007, \$1). O dionisíaco leva, portanto, à dissolução do eu e a uma liberação dos excessos pulsionais. Trata-se de um impulso com tendências destrutivas, que, sozinho, pode-nos levar à morte pela afirmação da vida, para inverter a fórmula que Bataille (1957/2013) utiliza para definir erotismo.

Assim descritos o apolíneo e o dionisíaco, fica evidente que o cisne branco representa o impulso apolíneo e o negro, o dionisíaco. A oposição entre esses dois impulsos nos interessará aqui na medida em que os consideramos como representativos de certos conflitos subjetivos contemporâneos.

Vale ressaltar, entretanto, que tal oposição não parece ser exclusividade da era contemporânea. Adorno e Horkheimer (1947), por exemplo, entendem que esse conflito acompanha a humanidade desde as origens da subjetividade:

A humanidade teve que se submeter a terríveis provações até que se formasse o eu, o caráter idêntico, determinado e viril do homem, e toda infância ainda é de certa forma a repetição disso. $\mathrm{O}$ esforço para manter a coesão do ego marca-o em todas as suas fases, e a tentação de perdê-lo jamais deixou de acompanhar a determinação cega de conservá-lo.

Os filósofos servem-se ainda da história de Ulisses para retratar o embate em questẫo. O dionisíaco - ou, como preferem Adorno e Horkheimer (1947), as "potências da dissolução" - é representado pelas sereias que seduzem "com a promessa irresistível do prazer” (Adorno \& Horkheimer, 1947). Para não mergulhar no nada, a astúcia apolínea de Ulisses concebe duas formas de resistência. A primeira é a que ele prescreve aos marinheiros:

Ele tapa seus ouvidos com cera e obriga-os a remar com todas as forças de seus músculos. Quem quiser vencer a provação não deve prestar ouvidos ao chamado sedutor do irrecuperável e só o conseguirá se conseguir não ouvi-lo. Disso a civilização sempre cuidou. Alertas e concentrados, os trabalhadores têm que olhar para frente e esquecer o que foi posto de lado. A 
tendência que impele à distração, eles têm que se encarniçar em sublimá-la num esforço suplementar. É assim que se tornam práticos (Adorno \& Horkheimer, 1947).

A segunda é a que Ulisses escolhe: fica com os ouvidos descobertos, mas amarrado ao mastro. Limita, portanto, seu poder de ação para não se deixar levar apesar de si mesmo. Essa, ao que parece, é a saída do dever moral - da limitação autoimposta.

Em uma sociedade que Lipovetsky (2005) pode chamar de pós-moral devido ao "crepúsculo do dever", não é difícil perceber que é a primeira forma de resistência que ganha força. Ela busca apoio no desenvolvimento tecnológico, seguindo um caminho bastante próximo daquele antevisto por Huxley (1932/1980) em seu Admirável mundo novo ${ }^{4}$. Voltemos à análise do filme Cisne Negro e tentemos, com base nele, desenvolver um diagnóstico mais detalhado da posiçáo da ética contemporânea frente ao embate entre Apolo e Dionísio.

Leroy, determinado a encontrar uma bailarina capaz de bem expressar seus movimentos de duas maneiras opostas - ou seja, formal e contidamente (apolíneo) enquanto cisne branco, e sensual e impulsivamente (dionisíaco) enquanto cisne negro -, convoca algumas bailarinas do grupo, entre elas Nina, para um teste. Quando Nina interpreta o cisne branco, Leroy se aproxima e diz: "Se eu estivesse procurando uma bailarina para interpretar somente o cisne branco, você seria a escolhida". Sua interpretação do cisne negro, entretanto, carece de sensualidade e de desprendimento do detalhismo formal.

No dia seguinte, Nina vai à sala de Leroy pedir que ele lhe dê uma segunda chance. Leroy a beija. Nina reage mordendo seu lábio e sai da sala. Aparentemente, a mordida revela a Leroy a faceta dionisíaca de Nina, levando-o a selecioná-la para o papel principal. Uma vez escolhida, o desafio de Nina será aproximar-se do dionisíaco. Essa trajetória de aproximação é retratada no filme por uma metamorfose da personagem em cisne negro. Tal metamorfose, entretanto, não se dará sem intensa turbulência subjetiva e dilaceração da estrutura egoica de Nina.

Como figura de referência para a transformaçấo de Nina, entra em cena outra bailarina, Lily. Se Nina, contida e perfeccionista, é a própria encarnação do apolínio, Lily, impulsiva, incontida e despreocupada, personifica o dionisíaco. Lily acaba se tornando uma espécie de alter-ego de Nina e a fusão das duas culmina, primeiro, em uma relação sexual/masturbação e, por fim, em um assassinato/suicídio. Erotismo e morte: Bataille (1957/2013) já observou a relação íntima entre os dois, que pressupóem uma diluiçấo do eu, seja em Eros, seja em Tânatos. 
Para entendermos de que forma o conflito de Nina pode ser visto como uma representação de certos conflitos subjetivos típicos da cena contemporânea será necessário voltarmos ainda a alguns diagnósticos que Lipovetsky (2007) apresenta como particulares de nossa "sociedade de hiperconsumo". O autor inicialmente descreve a análise de Jean Brun, que "procurou teorizar a ressurgência de Dionísio no coração das sociedades de abundância tomadas pelo êxtase do sexo, do psicodelismo, bem como pelas 'fúrias do consumo'" (Lipovetsky, 2007, p. 207). O indivíduo contemporâneo, segundo tal análise, buscaria no consumo uma espécie de libertação de uma existência insípida.

Embriagado pelo consumo, imerso em uma torrente de solicitações, à espreita de "viagens" e de insólito, de transgressôes e de músicas inebriantes, o homem dionisíaco não tem outro intuito senáo romper os limites do seu Eu, livrando-se de todo centro e de toda subjetividade num paroxismo de sensaçôes e de pulsaçôes do desejo (Lipovetsky, 2007, p. 208).

Análise semelhante propõe Maffesoli (2003, p. 12) ao declarar que "a sombra de Dioniso se propaga em nossas megalópoles”. Para o sociólogo francês, o comportamento dionisíaco é um contraponto trágico a uma busca otimista e dramática, levada a cabo nos últimos séculos, pelo máximo de produtividade e progresso. Essa atitude apolínea estaria se saturando e, com isso, preparando o cenário àquilo que Maffesoli designa por sensibilidade trágica: um elogio ao "instante eterno", que imobiliza o tempo através do afeto compartilhado e eleva as aparências coletivas acima de uma identidade individual. Trata-se de uma atração apaixonada pelo grupo, combustível de um cotidiano lúdico em que nossa existência não passa de uma sucessão de instantes. Exemplos da emergência da paixão dionisíaca seriam as marchas/causas/redes sociais, gay parades, flash mobs, festas rave, etc.

Nesse contexto dionisíaco, haveria a coexistência de um sentimento trágico, vazio e silenciosamente ensurdecedor, o qual é constantemente explorado nos filmes de Darren Aronofsky. Em "Réquiem para um sonho" (Requiem for a Dream, 2000), os personagens são aprisionados, sob diferentes formas de vícios, à angústia existencial decorrente de um "mundo ideal" que nunca chega. Outro exemplo é Randy, protagonista de "O lutador" (The Wrestler, 2008), que, embora seja admirado pelo grande público da luta-livre, não encontra meios para reconquistar o amor de sua filha. Para comentar tal recorrência temática em Aronofsky, podemos usar uma frase de Maffesoli (2003, p. 14): "a verdadeira vida não tem projeto porque náo tem objetivo definido". Por isso, os heróis paradoxais da pós- 
-modernidade estariam sempre em queda e em ascensão, de maneira pulsante e repetitiva - a experiência de um tempo místico e trágico, da repetição, que é especialmente destacada em "A fonte da vida" (The Fountain, 2006). Esse tempo circular, desistoricizado, nos remete à infância - uma infância eterna:

[...] assim como a figura do homem adulto e realizado, dono de si e da natureza, dominou a modernidade, não veríamos ressurgir, nesta pós-modernidade nascente, o mito do puer aeternus, essa criança eterna, brincalhona e travessa, que impregnaria modos de ser e pensar? (Maffesoli, 2003, p. 12).

Lipovetsky (2004; 2007), entretanto, questiona a acuidade de tal interpretação: como falar em uma tendência de dissoluçáo coletiva do eu em uma cultura obcecada pelo individualismo, pelo conforto, pelo bem-estar e pela "qualidade de vida"? Como falar em tendências dionisíacas em uma cultura obstinada a contabilizar riscos (risco de comer mal, risco de não fazer exercício, risco da violência, risco das doenças sexualmente transmissíveis, riscos de desastres ambientais etc.)? Estaríamos diante de um paradoxo, como sugere o título de sua obra $A$ felicidade paradoxal? É fácil observar, ao menos, a existência de múltiplos conflitos.

Especialmente, a dimensão dionisíaca das formaçôes subjetivas contemporâneas se choca com outra dimensão, que Lipovetsky (2007) associa à figura do Super-Homem, mas que poderia muito bem ser associada a Apolo: escapando à mentalidade moderna de normalização e regulação de corpos instigados à docilidade e à ordinariedade, o presente desregulamentado exalta a figura do indivíduo guiado pela superação e que obtém seu gozo através da conquista pessoal e do reconhecimento alheio. Trata-se da obsessão - de inclinação hiperindividualista e narcísica - pela performance (Ehrenberg, 2010), pela eficácia e pelo sucesso.

Em suma, o pragmatismo dos marinheiros de Ulisses retorna fantasiado de potência heroica. Aqui, a renúncia ao êxtase dionisíaco é justificada por uma suposta maximização dos prazeres apolíneos e não pela obediência surda ou por qualquer espécie de "ascetismo leigo", tal como no diagnóstico de Weber (1905/2004) sobre o espírito do capitalismo. Trata-se de uma economia dos prazeres muito diversa daquela pregada por Epicuro (2002) - evidentemente mais propenso a resistir ao mergulho no dionisíaco à maneira de Ulisses do que à maneira dos marinheiros -: ao invés da frugalidade epicuriana, a alimentação funcional (dos suplementos alimentares às altas doses de café e energético); ao invés da amizade, a dedicação para vencer os adversários; ao invés da conversa, o entretenimento; ao invés da filosofia, a completa instrumentalização do pensamento; ao invés da tentativa de suprimir o medo da morte e o sofrimento através de pensamentos ${ }^{5}$, a 
tentativa de prolongar a vida por meio de sujeição irrefletida às tecnologias biomédicas. Se nos afastamos de Epicuro, entretanto, é fácil ver que nos aproximamos da filosofia de vida em voga no já citado Admirável mundo novo.

Assim como no romance de Huxley (1932/1980), essa nova inclinação ética do desempenho e do entretenimento faz declinar a moral (entendida como âmbito dos deveres e normas), dando lugar à cultura do risco, na qual de antemão são avaliadas a "utilidade" (no sentido utilitarista) das açôes individuais. A busca pela maximização de utilidade se mescla à busca da performance, as duas recorrendo, muitas vezes, ao afă medicalizante que justifica desde o uso de anabolizantes para atletas até a receita de psicotrópicos fortes a crianças com diagnóstico de déficit de atenção ou de outras psicopatologias fantásticas.

Envolvidos na crença neoliberal de um mundo com infinitas oportunidades à disposição daqueles obstinados a alcançá-las, indivíduos são educados dentro da liturgia super-heróica de que grandes poderes são possíveis, mas trazem consigo grandes responsabilidades. Responsabilidades significam, aqui, maiores preocupaçôes com o "bom" (i. e. útil) uso de seus poderes. Não se trata de deveres, vale reiterar: o utilitarismo já desbancou todas as deontologias. E mais: colocou em evidência o polo negativo de sua doutrina - o foco passa da maximização do prazer da maioria a um princípio do náo-dano elevado à última potência. Some-se a tal visão a paixão contemporânea pelas probabilidades ${ }^{6}$ e teremos os ingredientes básicos da cultura do risco. Qualquer indivíduo que tenha visto um pouco de televisão ou lido algumas edições de jornais nos últimos anos sabe que "avaliação de riscos" não é mais jargão restrito aos meios empresariais.

Em Cisne negro, é possível observar como essa orientação performática apolínea entra em conflito com as tendências dionisíacas que Nina é instigada a desenvolver. Há, por exemplo, a cena em que Nina vai à boate com Lily e, estimulada por esta, acaba consumindo ecstasy e álcool em excesso, comprometendo o treino do dia seguinte. Tal conflito entre a orgia e a performance é bastante representativo da cena contemporânea: de um lado, excesso de álcool e de aperitivos banhados em gordura, de outro, ração humana e suplementos nutricionais variados; de um lado, cresce a obesidade, de outro, o fisiculturismo. E o mais importante: o indivíduo contemporâneo é instado, como Nina, a exceder-se nos dois polos, missão virtualmente impossível e geradora de ansiedade extrema.

Quando não há trégua entre os dois polos, e um quer prevalecer absoluto, pode-se culminar, por um lado, nas compulsões (transtorno alimentar compulsivo, toxicomania etc.) e, por outro, nas mortificaçóes (anorexia, trabalho excessivo, lesões por excesso de treino etc.). Vemos que a pulsão apolínea, assim como a dionisíaca, pode ser destrutiva. 
Nina é o exemplo perfeito da guerra entre Apolo e Dionísio, guerra esta que dilacera o corpo e o espírito: por um lado, é obsessiva com a performance a ponto de violentar-se, por outro coça-se compulsivamente. É significativo, nesse sentido, que o primeiro indício da transformação de Nina em cisne negro seja uma ferida que se abre devido ao ato compulsivo de coçar. Na medida em que a transformação evolui, observa-se que esta primeira ferida era já o início da abertura pela qual as asas do cisne negro desabrochariam. Ou seja, a coceira compulsiva revela insidiosamente um Dionísio acuado que se fortalece aos poucos.

Na cena contemporânea, Apolo e Dionísio ganham força através de discursos e dispositivos. Fortalecendo Apolo, aparecem, principalmente, os imperativos da boa-forma e da saúde a todo custo. A elevação do sucesso profissional e financeiro continua, muitas vezes, a aparecer como "fim último" da vida humana, dando continuidade ao "espírito do capitalismo" identificado por Weber (1905/2004). Com efeito, meios e fins confundem-se a tal ponto na ética contemporânea que, atualmente, a felicidade pode despontar "[...] como recurso estratégico para a otimização da saúde, da sociabilidade e da produtividade" (Freire-Filho, 2010, p. 50). Ou seja, já não se pode mais dizer, junto com Aristóteles (2009, p. 48), que "[...] ninguém opta pela felicidade [...] como um meio para qualquer outra coisa que seja, salvo ela mesma”. Além de tais discursos, surgem ainda diversos "dispositivos de ajuda" (Bezerra Jr., 2010) apolíneos: livros de autoajuda, terapias as mais diversas, e, especialmente, drogas. Sucesso profissional e escolar através do uso de Ritalina; superação de desafios e angústias através de ansiolíticos como o Rivotril; ordem e contenção corporal por meio de inibidores de fome.

Fortalecendo Dionísio, encontramos o estado de deriva resultante da crise dos referenciais modernos, o álcool e os discursos apologéticos do gozo momentâneo, tais como os que Lily repete no filme quando procura fazer aflorar o lado dionisíaco de Nina: "live a little [viva um pouco]", "you really need to relax [você realmente precisa relaxar]” etc. Expressóes semelhantes não raro são encontradas em uma vasta gama de produtos midiáticos - de revistas de aconselhamento a programas de auditório -, culminando em slogans publicitários que recebem status de mantra nos dias de hoje.

Em uma campanha da marca Diesel ${ }^{7}$, por exemplo, tais exortaçóes dionisíacas são levadas às últimas consequências: "Be stupid [seja estúpido]" é o que ela nos aconselha. Em tal campanha, lemos, dentre outras, as seguintes chamadas: "Smart critiques. Stupid creates [Esperto critica. Estúpido cria]", "Smart may have the brains, but stupid has the balls [Esperto pode ter cérebro, mas estúpido tem colhôes]" e "Smart says no. Stupid says yes [Esperto diz não. Estúpido diz sim]". As imagens que aparecem nas peças da campanha mostram jovens em atividades 
tolas, tais como: mostrar os seios para a câmera de vigilância (figura 1), entrar na cela de macacos para brincar com eles, roubar cones de sinalização para usar sobre a cabeça, pular em cima do namorado de uma distância náo muito segura etc.

Figura 1 - peça da campanha Be Stupid, da marca Diesel

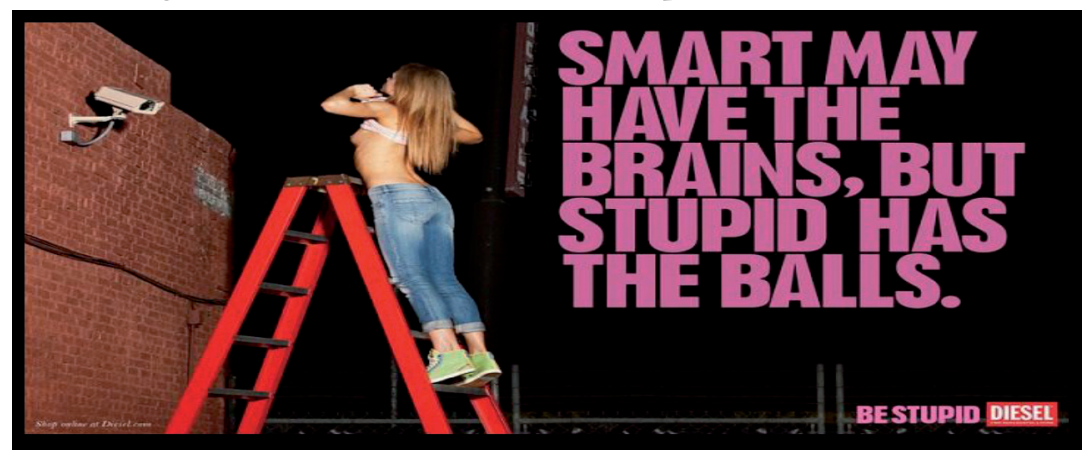

Assim, racionalidade e "bom senso" são sumariamente atacados como adversários de um Dionísio que exige poderes irrestritos. É clara a inspiração nietzschiana desse "estúpido" idealizado pela campanha: tal como o Übermensch dionisíaco, ele tampouco critica (nos moldes da crítica ilustrada), dado que a verdade é relativa, mas sim, cria, já que todo discurso e a própria verdade são uma invenção. Ele tem a coragem de ser "livre", desbanca os ídolos que oferecem aos fracos a muleta dos ideais (apoio que também aprisiona) e, acima de tudo, diz sim à vida.

O estúpido trata, portanto, de liberar as próprias potências, de deixar fluir as pulsôes sem restriçóes, sem consideraçóes ao perigo, ao risco, aos deveres ou aos ideais. Desamarrado e sem cera no ouvido, ele escuta o canto das sereias e mergulha no mar sem pensar duas vezes. Ele é "estúpido" porque a "esperteza" pressupóe negação - já que ela exige adequação ao que é tido como sensato. Sensato, diria o estúpido, é justamente não ser sensato, paradoxo que se evidencia em outro slogan da campanha em questão: "smart had one good Idea and that idea was stupid [esperto teve uma boa ideia, e essa ideia era estúpida]”.

Como é fácil notar, o estúpido da Diesel ou o "espírito livre" nietzschiano não são as figuras mais representativas do sujeito-consumidor contemporâneo, embora não se possa desprezar o fato de elas terem ganhado destaque no discurso atual.

Uma recente campanha da cerveja Devassa parece capturar melhor o espírito do nosso tempo quando fala de uma dimensão dionisíaca presente em cada um de nós: "todo mundo tem um lado devassa", afirma o slogan. A natureza de tal "lado devassa” é explicada no site da campanha: 
Vivemos em uma sociedade cheia de regras. [...] Aos poucos, todas essas regras vão tirando nossa criatividade e alegria. Mas, ao mesmo tempo, algumas coisas [...] nos fazem sair desse cotidiano do mundo bem comportado. [...] É nessas horas que a gente fala duas vezes antes de pensar, que a gente perde a compostura, mas não perde a piada. É quando a gente paga mico, [...] perde a hora, [...] pisa na bola, quando a gente faz o que tem vontade de fazer. É aí que aparece o outro lado de cada um de nós. O nosso lado descontraído, [...] despirocado, [...] desencanado. [...] no fundo, no fundo, todo mundo tem um lado devassa ${ }^{8}$.

Aqui, Dionísio é exaltado como aquilo que se contrapóe à consensual e resignada presença de Apolo em nossas vidas. A mensagem sublinear é que beber uma Devassa equilibraria nosso cotidiano apolíneo com pitadas dionisíacas, tornando-nos mais alegres, criativos e aptos a relativizar regras e normas. Propóe-se uma alternância possível entre as duas forças, mas ignora-se que elas se chocam, como demonstra a cena da ressaca de Nina, citada acima.

Passando para o outro lado do espectro, não faltam, é claro, propagandas que enaltecem Apolo. Será desnecessário reproduzir aqui as inúmeras peças publicitárias que evocam ideais de beleza, sucesso profissional e desempenho atlético. Com efeito, aos que acreditam que a propaganda é essencialmente dionisíaca em sua função de despertar desejos pelas mercadorias, é importante reproduzir a constatação de Lears (1995, p. 10, tradução nossa) de que, na história da propaganda,

[...] o prazer esteve subordinado, em ampla medida, a um objetivo mais amplo de eficiência pessoal. É certo que a sensualidade sobreviveu, mas cada vez mais envolta por um vocabulário de franqueza clínica. No geral - apesar da bem-vinda ressurgência da ironia, do humor, e mesmo do surrealismo nas últimas décadas - os valores administrativos (de controle) dominaram a maior parte da propaganda americana até o presente.

A propaganda transita, portanto, entre os polos da liberação e controle e, do mesmo modo, o consumo, intimamente relacionado aos discursos publicitários, é cenário de uma constante disputa entre dionisíaco e apolíneo. Do Rivotril ao álcool, do diet shake à feijoada, dos aparatos de musculação aos aparatos sexuais, da casa do saber à casa de swing, do confortável sedentarismo burguês ao turismo de diversão, do consumo conspícuo ao consumo de experiência, da poupança ao bilhete de loteria. Retoma-se aqui todo o dualismo descrito ao longo do texto em versão condensada: aonde quer que olhemos, na sociedade de consumo 
contemporânea, parece ser possível perceber a coexistência conflituosa, mas ao mesmo tempo complementar, entre Apolo e Dionísio.

Importa agora, para concluirmos este estudo, retomar e observar com mais cuidado as particularidades subjetivas representativas da fase atual deste conflito. Além disso, se o conflito entre o apolíneo e o dionisíaco manifesta-se na forma de um dilema subjetivo, qual é o papel desse dilema na formação ou dissolução de uma subjetividade adaptada à ética do consumo vigente? E, por fim, como poderíamos descrever essa ética?

Já ficou claro que, na cena contemporânea, apresentam-se como "bem" valores éticos em larga medida opostos, mas que se relacionam de formas curiosas. Observamos também que o mesmo indivíduo é agora instado a desempenhar com maestria os papeis dos cisnes branco e negro. Portanto, trata-se do conflito apolíneo-dionisíaco como elemento instaurador de condutas e visóes éticas contraditórias reiteradas por produtos midiáticos através das quais nos reconhecemos como sujeitos e nos credenciamos a julgar o outro e a realidade plural que nos cerca.

Procuramos, aqui, questionar leituras unilaterais, propondo que o cerne da ética contemporânea do consumo é o conflito entre duas éticas. Mostramos ao longo deste trabalho que as análises que tendem à uniteralidade costumam descrever a ética contemporânea do consumo ou como aquela da liberação de todos os desejos - ou seja, como essencialmente dionisíaca - ou como aquela do controle dos desejos, gerida pelas lógicas do risco, da performance individual e da manipulação do mercado - ou seja, como essencialmente apolínea. Portanto, o que está em debate aqui é o próprio entendimento do que seria essa "ética contemporânea do consumo", razão pela qual não oferecemos, de antemão, uma descrição da mesma.

A seguir, a partir do estudo desenvolvido até então, observaremos mais atentamente as estratégias da guerra entre Apolo e Dionísio com o objetivo de tornar mais claro e preciso nosso diagnóstico da ética contemporânea do consumo.

No ambiente performático da cena contemporânea, a lógica apolínea do desempenho, em uma curiosa virada, começa a se imiscuir até mesmo no dionisíaco, corroendo-o por dentro. Verdadeiro Cavalo de Tróia ético, estratagema digno de Ulisses. Se Apolo parece ceder, é para exaltar Dionísio em um culto invertido: o êxtase como meta - mas o verdadeiro êxtase não é justamente a dissipação da meta? O prazer como norma - mas o prazer não é, em larga medida, a dissipação da norma (que limita a potência)? Momento curioso nesse conflito imemorial. Como explicar este paradoxo "bipolar" no qual a ausência de lei reafirma a proibição? Se as barreiras à satisfação pulsional parecem ruir, elas na verdade se deslocam para dentro do campo do desejo: a culpa, como observa Žižek (2011), não emerge mais porque se ultrapassou a barreira, mas porque, mesmo sem barreira, 
não se chegou onde queria: "uma permissão que bloqueia o gozo" - problemática freudiana que somente agora se torna crucial, quando emerge por baixo do véu abandonado da repressão. A velha noção de uma vida harmoniosa reaparece, conforme identifica Žižek (2011), sob uma nova receita do mal-estar freudiano disfarçado de bem-estar social supostamente "esclarecido": se antes reprimíamos nossos desejos sexuais, hoje vivemos sob o mandato de gozar.

Baudrillard (1970/2010, p. 50) também observava a emergência desse paradoxo de um gozo que, erigido como norma, não pode ser senão signo do gozo trabalho simbólico: "A felicidade como fruição total e interior, felicidade independente de signos que poderiam manifestá-la aos olhos dos outros e de nós mesmos, sem necessidade de provas, encontra-se desde já excluída [...]". "O homem-ser consumidor considera-se como obrigado a gozar e como empresa de prazer e de satisfação, como determinado a ser feliz, amoroso, adulador/adulado, sedutor/ seduzido, participante eufórico e dinâmico" (Baudrillard, 1970/2010, p. 94).

No cenário atual, portanto, a guerra entre Apolo e Dionísio se desenrola em meio a intrincados subterfúgios e armadilhas. Não se trata mais (se é que se tratou algum dia) apenas de uma contenda superficial que poderia ser resolvida nos moldes "descontraídos" propostos pela propaganda da Devassa. Nina é o exemplo perfeito do sujeito contemporâneo justamente porque ela deve buscar o dionisíaco no seio mesmo de uma atividade apolínea: a performance no palco. Mas não se trata aqui de uma síntese trágica como a exaltada por Nietzsche (1872/2007), e sim de uma contradição que fica patente na propaganda da Diesel: a mensagem de exaltação do "estúpido" é veiculada no próprio registro da imagem de marca. O dionisíaco com etiqueta - seria esse, talvez, o emblema paradoxal da ética contemporânea do consumo.

\section{Referências}

Adorno, T., \& Horkheimer, M. (1947). Dialética do esclarecimento. Recuperado em 26 de julho, 2011, de: <http://www.nre.seed.pr.gov.br/umuarama/arquivos/File/educ_esp/fil_dialetica_esclarec.pdf>.

Aristóteles. (2009). Ética a Nicômaco. Bauru: Edipro.

Bataille, G. (2013). O erotismo. Belo Horizonte: Autêntica. (Trabalho original publicado em 1957)

Baudrillard, J. (2010). A sociedade de consumo. Lisboa: Edições 70. (Trabalho original publicado em 1970)

Bezerra Jr., B. (2010). A psiquiatria e a gestấo tecnológica do bem-estar. In J. Freire-Filho (Ed.) Ser feliz hoje: reflexão sobre o imperativo da felicidade (pp. 117-134). Rio de Janeiro: Editora FGV. 
Dawkins, R. (2006). The God delusion. London: Bantam Press.

Ehrenberg, A. (2010). O culto da performance: da aventura empreendedora à depressáo nervosa. São Paulo: Editora Idéias \& Letras.

Epicuro. (2002). Carta sobre a felicidade: (a Meneceu). São Paulo: Editora Unesp.

Freire-Filho, J. (2010). A felicidade na era de sua reprodutibilidade científica: construindo "pessoas cronicamente felizes". In J. Freire Filho (Ed.), Ser feliz hoje: reflexöes sobre o imperativo da felicidade (pp. 49-82). Rio de Janeiro: FGV.

Huxley, A. (1980). Admirável mundo novo. São Paulo: Abril cultural. (Trabalho original publicado em 1932)

Lears, J. (1995). Fables of abundance: a cultural history of advertising in America. New York: Basic Books.

Lipovetsky, G. (2004). Metamorfoses da cultura liberal: ética, midia e empresa. Porto Alegre: Sulina. Lipovetsky, G. (2005). A sociedade pós-moralista: o crepúsculo do dever e a ética indolor dos novos tempos democráticos. Barueri: Manole.

Lipovetsky, G. (2007). A felicidade paradoxal. São Paulo: Companhia das Letras.

Maffesoli, M. (2003). O instante eterno: o retorno do trágico nas sociedades pós-modernas. São Paulo: Zouk.

Nietzsche, F. (2007). O nascimento da tragédia: ou helenismo e pessimismo. São Paulo: Companhia das Letras. (Trabalho original publicado em 1872)

Portugal, D. B., \& Rocha, R. M. (2009). Como caçar (e ser caçado por) imagens: entrevista com W. J. T. Mitchell. E-compós, 12(1). Recuperado em 24 de junho, 2009, de: <http:// www.compos.org.br/seer/index.php/e-compos/article/view/376/327>.

Schopenhauer, A. (2001). O mundo como vontade e representação. São Paulo: Contraponto. (Trabalho original publicado em 1818)

Weber, M. (2004). A ética protestante e o espírito do capitalismo. São Paulo: Companhia das Letras. (Trabalho original publicado em 1905)

Žižek, S. (2011). O desejo, ou a traição da felicidade: entrevista com Slavoj Žižek. Recuperado em 26 de julho, 2011, de <www.zizek.weebly.com/texto-011.html>.

\section{Notas}

${ }^{1}$ Apesar de serem inicialmente definidas como pulsóes estéticas, Nietzsche (1872/2007) observa que elas possuem também facetas desestetizadas: o dionisíaco da licenciosidade e crueldade bárbaras em oposição à sensibilidade grega ao absurdo da existência; o apolíneo moralizante e racionalizante que tende ao socratismo em oposição ao esplendor dos deuses do Olimpo. Neste artigo, estamos utilizando apolíneo e dionisíaco de maneira livre, muitas vezes dando mais atenção a suas facetas desestetizadas do que a suas facetas propriamente estéticas. 
${ }^{2}$ Representação entendida aqui no sentido schopenhaueriano: algo da ordem do fenômeno.

${ }^{3}$ Nietzsche aproveita o termo que Schopenhauer (1818/2001) utiliza para explicar sua metafísica. Para Schopenhauer, a essência do mundo é uma Vontade una que se mostra repartida apenas no mundo como representaçáo (o véu de Maya hindu): apenas para o entendimento, ou seja, na representação, existiria individualidade. Apenas o mundo como representação seria regido pelo principium individuationis.

${ }^{4}$ Em Admirável mundo novo, Huxley (1932/1980) concebe um mundo dominado pela técnica: os embriôes são geneticamente manipulados e as crianças condicionadas para se conformarem às normas sociais suavemente e com gosto. Lá proliferam todas as formas de entretenimento e diversão enquanto a capacidade reflexiva e a sensibilidade estética são reprimidas tanto quanto possível. A irrupção de qualquer tipo de dúvida, melancolia, raiva etc. é imediatamente tratada com doses generosas de uma droga sintética chamada soma, que quase sempre reestabelece a disposiçấo boba-alegre tida como boa e normal. Quando ela não dá conta, os indivíduos antissociais são sumariamente condenados ao ostracismo. Enfim, tudo no Admirável mundo novo é orquestrado, com o auxílio das mais avançadas tecnologias, para que todos os habitantes levem uma vida perfeitamente bovina com o máximo de prazer e o mínimo de cultivo espiritual.

${ }^{5}$ Por exemplo: "Acostuma-te à ideia de que a morte para nós não é nada, visto que todo o bem e todo o mal residem nas sensações, e a morte é justamente a privação de sensações. A consciência clara de que a morte não significa nada para nós proporciona a fruição da vida efêmera, sem querer acrescentar-lhe tempo infinito e eliminando o desejo de imortalidade" (Epicuro, 2002, p. 27).

${ }^{6} \mathrm{O}$ famoso biólogo Richard Dawkins chega ao cúmulo de propor que se resolva o antigo problema da existência de Deus com base não apenas na ciência (Kant se revira na cova), mas, enquanto não se chega a uma "prova definitiva" (obviamente ele não explica de que tipo poderia ser essa fantástica prova), ele tem a excelente ideia de usar as probabilidades: "Either He [God] exists or he doesn't. It is a scientific question; one day we may know the answer, and meanwhile we can say something pretty strong about the probability" (Dawkins, 2006, p.48).

${ }^{7}$ Disponível em <http://www.creativeadawards.com/diesel-be-stupid-advertising-campaign/>.

${ }^{8}$ Disponível em <http://www.devassa.com.br/bemloura/index.html?isMaior=true\#/manifesto $>$.

Recebido em 05 de fevereiro de 2012 Aceito para publicação em 04 de setembro de 2012 